\title{
Male engagement in family planning in Togo: Evaluating couples counseling models
}

Breakthrough RESEARCH

Follow this and additional works at: https://knowledgecommons.popcouncil.org/departments_sbsr-rh How does access to this work benefit you? Let us know!

\section{Recommended Citation}

Breakthrough RESEARCH. 2018. "Male engagement in family planning in Togo: Evaluating couples counseling models," Activity brief. Washington, DC: Population Council. 


\section{Male Engagement in Family Planning in Togo Evaluating Couples Counseling Models}

\section{Breakthrough RESEARCH is evaluating group-based and home-based couples} counseling in Togo's Kloto district to determine the benefits of each approach and their suitability for scaling up. In this district, USAID's Maternal and Child Survival

Project has designed several male engagement and couples counseling programs that must be evaluated before a common counseling framework is put in place.

\section{WHY ARE WE DOING THIS ACTIVITY?}

Twenty years of literature has shown that gender normsor social expectations of men and women's roles and behaviors-affect couples' family planning decisions. Therefore, effective family planning counseling should engage both men and women in discussions about gender-equitable decision-making. Couples counseling programs have had particularly promising results to this end, improving partners' overall communication and family planning use.

In Togo's Kloto District, the Maternal and Child Survival Project has designed several male engagement and couples counseling programs with potential for scale. The models must be evaluated before a common counseling framework is put in place in the West Africa region.

\section{HOW WILL THIS ACTIVITY BE IMPLEMENTED?}

Breakthrough RESEARCH is evaluating two types of couples counseling to assess their benefits and feasibility and to determine which elements of each are best suited for roll-out on a broader scale. The two counseling models-groupbased and home-based-will be implemented in separate townships (cantons) in Togo's Kloto district.

- Canton of Kpadapé (4 villages) will host group-based couples counseling. Community health workers (CHWs) will deliver the sessions, featuring a mixture of digital

\section{ACTIVITY SNAPSHOT}

Assess the relative costs and benefits of two couples counseling methods

LEAD PARTNER

CONTACT

Institute for Reproductive

Health (IRH) at Georgetown University

ANTICIPATED TIMELINE

$2018-2019$

GEOGRAPHIC LOCATION

Togo

videos and group reflection. Counseling will be offered to both mixed and same-sex groups.

- Canton of Kpimé (15 villages) will host in-home couples counseling visits. CHWs will deliver the sessions using counseling cards.

In both locations, CHWs, health service providers, and counselors will be trained on four modules: family planning; couple communication; gender norms; and intimate partner violence.

The study team will investigate three questions in each location:

- What processes and elements are needed-including resources, tools, and provider behavior profiles-to successfully roll-out and assess the two modalities of couples counseling in Togo? 
